\title{
Ambientes sonoros de aprendizaje: una estrategia didáctica que promueve la educación ambiental
}

\author{
Sound environments of learning: a didactic strategy that \\ promotes environmental education
}

\begin{abstract}
Ambientes sadios da aprendizagem: uma estratégia didática que promova a educação ambiental
\end{abstract}

José Leonardo Ruiz Méndez

Candidato a doctor en educación y cultura ambiental

Universidad Surcolombiana

leonardo1@usco.edu.co

\section{Resumen}

El presente escrito recoge una experiencia de educación ambiental aplicada en los cursos de historia de la música contemporánea, historia del arte colombiano y didáctica de la música, los dos primeros pertenecientes a la licenciatura en educación artística y cultural y el último a la licenciatura en educación infantil de la Universidad Surcolombiana. La investigación, tiene como fines, por una parte, sensibilizar a los estudiantes sobre la crisis ambiental derivada del modelo de desarrollo actual, así como las causas que la han provocado. De igual manera, busca implementar en el aula de clase la estrategia didáctica denominada Ambientes Sonoros de Aprendizaje (ASA) como una alternativa pedagógica que se enfoca en la Geopoética del Habitar, por cuanto vincula al aula de clase la comprensión de los entornos cultural y ecosistémico en relación a las escrituras individuales y colectivas que hacemos los seres humanos sobre el planeta. La metodología implementada es de tipo cualitativo con enfoque descriptivo, contempla el desarrollo de seis fases a través de las cuales se propende por el encuentro de los tres grupos de estudiantes donde uno de estos se encarga de preparar la muestra ASA. Los resultados obtenidos muestran una definición de Ambientes Sonoros de Aprendizaje, así mismo, la manera como se realizaron las actividades, los aportes que brindan a la formación de los estudiantes, y finalmente los aprendizajes alcanzados manifestados por el estudiantado encuestado. 
Palabras Clave: Ambientalización de la educación, didáctica, historia musical, crisis ambiental, habitar.

\begin{abstract}
The present paper gathers an experience of applied environmental education in the courses of history of the contemporary music, history of the colombian art and didactics of the music, the first two pertaining to the degree in artistic and cultural education and the last one to the degree in education child of the Surcolombiana University. The research aims, on the one hand, to sensitize students about the environmental crisis derived from the current development model, as well as the causes that have caused it. In the same way, it seeks to implement in the classroom the didactic strategy called Sound Environments of Learning (SEL) as a pedagogical alternative that focuses on the Geopoetics of Living, as it links the classroom with the understanding of the cultural and ecosystem environments in relation to the individual and collective writings that human beings do on the planet. The methodology implemented is of a qualitative type with a descriptive focus, contemplating the development of six phases through which the meeting of the three groups of students where one of these is responsible for preparing the SEL sample is encouraged. The results obtained show a definition of Sound Environments of Learning, likewise, the way in which the activities were carried out, the contributions that provide to the formation of the students, and finally the learning achieved manifested by the surveyed student body.
\end{abstract}

Keywords: Environmentalization of education, didactics, musical history, environmental crisis, living.

\title{
Resumo
}

Este escrito reflete uma experiência de educação ambiental aplicada cursos de história da música contemporânea, história da arte colombiano e educação musical, os dois primeiros pertencente ao bachelor of arts e educação cultura e finalmente para o bacharelado em educação filho da Universidade Surcolombiana. A pesquisa visa, por um lado, sensibilizar os estudantes sobre a crise ambiental derivada do atual modelo de desenvolvimento, bem como as causas que a causaram. Da mesma forma, pretende implementar na estratégia de ensino em sala de aula chamado ambientes sonoros Aprendizagem (ASA) como uma alternativa educacional que incide sobre os Geopoéticas de Habitar, porque liga a compreensão sala de aula do ambiente cultural e ecossistema em relação aos escritos individuais e coletivos que os seres humanos fazem no planeta. A metodologia é implementada com abordagem qualitativa descritiva envolve o desenvolvimento de seis estágios através dos quais se pretende reunião 
dos três grupos de estudantes, onde um deles é responsável por preparar a amostra ASA. Os resultados mostram uma definição de ambientes de aprendizagem Soundscapes, também, como as atividades foram realizadas as contribuições que oferecem formação para os estudantes e conquista finalmente aprendendo expressos pelos alunos pesquisados.

Palavras-chave: Ambientalização da educação, didática, história musical, crise ambiental, vida.

\section{Introducción}

El mundo contemporáneo se encuentra en una situación de crisis ambiental que exige reflexionar sobre la necesidad de reconocer como propias las problemáticas generadas por la forma como la especie humana ha habitado el planeta.

En este sentido, el accionar humano ha dejado una huella compleja y agresiva en la naturaleza, evidenciada en la afectación de los ecosistemas e incluso en el funcionamiento de los ciclos biogeoquímicos. Entre estas consecuencias se encuentran: El calentamiento global de tipo antropogénico, la trasgresión de los límites del ciclo del nitrógeno y del fósforo, la acidificación de los océanos, la destrucción de la capa de ozono, el intenso cambio de uso y cobertura del suelo, la pérdida creciente de biodiversidad, entre otras (Delgado et al 2013 p. 16).

Ante este panorama, el abordaje de una educación ambiental que reflexione sobre la manera como deberíamos habitar el planeta, puede contribuir como solución a esta problemática. Un habitar de la tierra no en el sentido político (propiedad), ni económico (división de la tierra), sino en el sentido de tejido de vida simbólico-biótico (Noguera 2012, p.2). Que considere que "el modo como tú eres, yo soy, la manera según la cual los hombres somos en la tierra es el habitar" (Heidegger, 1994, p. 129). Que relacione el habitar con el sentido de alteridad entendiendo que no es solo con otros seres humanos con quienes tejemos las relaciones de sentido de la existencia, sino con todos los seres de la naturaleza (Guerrero, 2002, p.30). Que incorpore los postulados de la Geopoética la cual es considerada como "un saber posible para descifrar e interpretar el signo del habitar" (Pineda, 2014, p.49). Una educación ambiental que se caracterice por ser crítica, que lleve a entender y a comprender las leyes que regulan los ecosistemas, para así poder enfrentar la crisis ambiental, construyendo actitudes éticas y formas de comprensión y respeto por los ecosistemas (Noguera, 2000, p. 113). Que reconozca que la tierra no nos pertenece, por el contrario pertenecemos a ella.

Teniendo en cuenta lo anterior, esta investigación da respuesta a la necesidad de vincular lo ambiental al aula de clase, aprovechando el 
énfasis que tiene el microdiseño curricular de cada uno de los cursos trabajados.

\section{Un poco de historia sobre la problemática ambiental}

Se ha creído que el ser humano como especie, ha sido la encargada de desorganizar el maravilloso orden ecosistémico. ¿Cómo se llegó a esta situación?

En los mitos griegos, Prometeo y Tántalo, en el filósofo Platón, en las leyendas babilónicas, la herencia judeocristiana y la influencia del capitalismo artístico podemos hallar algunas respuestas.

De un lado, el avance de la técnica se ve reflejado en el mito de Prometeo cuando roba del cielo de los dioses el fuego y lo regala como dádiva a los hombres. Con el fuego empieza el desarrollo civilizatorio, por eso es venerado como el dios de la producción, de la artesanía y del desarrollo civilizatorio en general. Prometeo es visto como un hombre rebelde que se levanta frente a los dioses, deja de ser un dios y se transforma en hombre. Este mito griego sirve como una cantera para la reconstrucción mítica de una rebeldía emancipadora la cual es realizada por la sociedad moderna a partir del Renacimiento (Hinkelammert, 2006). La idea de la acumulación proviene del mito de Tántalo, el cual es apreciado por los dioses del olimpo e invitado frecuentemente a las fiestas y banquetes que estos realizaban con ocasión de celebrar logros, desgracias, pilatunadas y resultados de la competitividad divina frente a los hechos de los seres terrenales. No contento con todas las prebendas que se le otorgaban, inició los robos de los néctares y la miel para regalárselos a sus amigos de farra. Tántalo entonces, representa la idea de crecimiento acumulativo.

El filósofo griego Platón en la "Teoría de los dos mundos", planteó que el universo tiene dos estructuras, una material (mundo sensible) y otra inmaterial (mundo inteligible de las ideas). En el mundo material las cosas nacen, crecen, se reproducen y mueren, mientras que el mundo inmaterial es eterno. Los dos mundos tienen como función establecer el ser. Los objetos materiales del mundo sensible, son una copia de los objetos que hay en el mundo inteligible. Platón considera entonces, que el mundo de las ideas es el auténtico mundo; sin embargo, se tiene la sensación de vivir en un mundo material.

Como efecto de lo propuesto por el pensador, hoy se habla de una "visión escindida de occidente" en la que se plantea una "relación intrínseca de poder del alma sobre el cuerpo, del espíritu sobre la materia, de lo celestial sobre lo terrenal, de lo interior sobre lo exterior" Noguera (2014, pág. 30). La visión judeocristiana y platónica de la que hablamos llevó a que la cultura occidental se construyera sobre el desprecio por la terrenalidad, la carnalidad y el cuerpo como lugar de lo placentero, lo que a su vez produjo 
la consolidación de la creencia de que la naturaleza era ilimitada y estaba disponible para la racionalidad tecno-científica infinita del ser humano (Noguera, 2004, p. 29). Así mismo de las primitivas leyendas babilónicas se ha heredado la creencia de que el hombre comete un error al acceder al árbol de la ciencia y descubrir aparentemente los secretos de la naturaleza. Costándole así el destierro del paraíso (Ángel-Maya, 2013).

De otra parte, se menciona que el capitalismo artístico ha conseguido apoderarse de los ideales de libertad absoluta, el valor de soñar, el placer, la vida creativa y la realización individual que propusiera el arte en los siglos XVIII y XIX (Lipovetsky y Serroy, 2015, p. 326), para implementar todo su accionar productivo basado en una economía de consumo que finalmente afectaría la relación naturaleza-cultura.

Como resultado, se observa que estos saberes, creencias, mitos y leyendas fueron transmitidos a la cultura occidental y difundidos por todo el planeta a través de la colonización europea, sepultando o relegando a un segundo plano las otras concepciones regionales, como las que predominaban en América en la época precolombina (Ángel-Maya, 2013).

Una consecuencia importante de la aplicación de estas maneras de comprender el mundo, es la separación entre ciencias naturales y ciencias sociales la cual muestra el alejamiento del hombre de la naturaleza. Lo ético no opera en las ciencias naturales y en las ciencias sociales lo ético sólo opera entre humanos. El pensamiento moderno nos enseñó a estudiar la naturaleza en partes, volviéndola objetiva, es decir estudiándola separadamente. De esta manera, no hemos podido comprender la naturaleza, ni se han podido descubrir sus secretos. La manera como estamos conociendo no nos permite conocer cómo es la trama de la vida. En conclusión, las ciencias naturales han sido una ciencia sin hombre y las ciencias sociales han sido una ciencia sin naturaleza (Ángel-Maya, 2013).

\section{Marco contextual}

Como la modernidad ha traído avances científicos y tecnológicos para cubrir ciertas necesidades humanas, es necesario reconocer algunos efectos de la división entre Naturaleza y Cultura que ha generado la implementación de dicho pensamiento occidental, entre los cuales se hallan el ambiental, el humano (educativo), el social (medios de comunicación) y el artístico (musical):

- Debido a que la tierra se ha considerado como un "recurso" de dominio del cual extraer riqueza, en el desarrollo de la ciencia y la tecnología como ideal de la modernidad, no se previeron las consecuencias ecosistémicas ni la alteración de los ciclos de regulación natural producto de la implementación 
del denominado "Metabolismo Socioeconómico", en el cual se argumenta que al igual que los organismos vivos, los sistemas sociales "mantienen un intercambio continuo de materias y energía con su medio ambiente que permiten su funcionamiento, crecimiento y reproducción" (FischerKowalski y Haberl 2000). Esto trajo como resultado la crisis ambiental reinante que sobrepasa todo límite.

- En el ámbito humano, el pensamiento moderno se perfiló en "conseguir la libertad por medio del ejercicio del pensar racional" (Noguera, 2000, p. 142), lo que conllevó a la desnaturalización del ser humano y a una vivencia antropocéntrica de la vida la cual ha sido aprovechada para "promover las libertades del consumidor y elogiar con entusiasmo el consumo como el camino más corto y seguro para alcanzar la felicidad" (Bauman y Mazzeo 2013, p. 52).

- En el campo educativo, la implementación del pensamiento occidental trajo como consecuencia un "énfasis desproporcionado en el desarrollo de un tipo de racionalidad, la lógicomatemática, enviando a un plano menos importante, otros tipos de inteligencias, de racionalidades y de formas de conocimiento" (Noguera, 2004, p. 75). Esto explica la importancia que tienen las profesiones relacionadas con lo cuantificable, lo medible, lo administrativo, lo económico, lo comunicativo, en síntesis, lo que genera riqueza a través de la explotación de la naturaleza. En tal sentido, la educación formal, "ciega por los éxitos económicos que proporcionaban la ciencia y la tecnología modernas a las clases y grupos que poseían los medios de producción y el poder, se colocó al servicio de la ideología de dominio de la naturaleza para fines pretendidamente científicos" (Noguera, 2000 p. 107). Así mismo, en el campo educativo "desde la perspectiva cientificista, el sujeto de la educación es el sujeto intelectual, o cartesiano. Es, por tanto, un sujeto sin cuerpo" (Noguera, 2004, 91). Una idea positivista de dominio que trasciende la esfera ecosistémica y ubica al ser humano como un objeto por conquistar que es necesario subyugar para garantizar el mantenimiento de los ideales económicos de prosperidad y de continuo crecimiento de la modernidad. En este sentido, Bauman y Mazzeo argumentan que se usa la depravación como "la estrategia más inteligente para el desposeimiento". Por cuanto a través de esta se logra: 
Desviar la atención (mediante la tentación y la seducción) de lo que es la tarea de adquirir un adiestramiento y, en consecuencia, también de lo que es "relevante en la vida" (...) es una técnica insidiosa (...) que convierte en placentera la constante privación, y que genera una servidumbre que es percibida y sentida como libertad de expresión (Bauman y Mazzeo 2013, p. 43).

Lo que quieren decir los autores es que el libertinaje o el desenfreno que promueve la modernidad, ha sido conquistado por los intereses económicos para hacer sentir la necesidad de calmar una carencia o de alcanzar algo que es importante. En consecuencia, esa privación es sosegada con la acción de comprar o de consumir, la cual "sirve como medida básica para evaluar nuestro lugar y nuestra calificación social en la carrera para alcanzar el éxito en la vida, es el grado de nuestra actividad como compradores y la facilidad con que desechamos un objeto de consumo para reemplazarlo con otro "nuevo y mejor" (Bauman y Mazzeo 2013, p. 99).

- En cuanto a los medios de comunicación, "que bien se han llamado en los últimos tiempos mediaciones por su carácter constructor de intencionalidades de la conciencia y de la corporeidad han liderado la estetización del mundo de la vida cotidiana" (Noguera, 2004, 140). Se cree que dicha estetización, alude a la capacidad de expresión que tiene el ser humano para dar forma al mundo, pero en este caso, manifestada de manera reduccionista como consecuencia de la intervención diaria de los medios de comunicación que pregonan los principios de la modernidad.

- En lo que respecta al arte, éste "se concibe entonces, como aquello que está alejado de lo ambiental (entendido como todo lo que se refiere a la relación entre cultura $y$ ecosistema) como una creación única y exclusiva del espíritu y, por tanto, perteneciente por entero al reino de la libertad" (Noguera, 2000, pág. 14). En consecuencia, por ejemplo, la OCDE (Organización para la Cooperación y el Desarrollo Económicos) considera el arte como industria cultural que genera riqueza "la economía de la cultura y las 'industrias creativas' juegan funciones clave en la economía y el crecimiento de muchos países de la OCDE. La porción relativa de las industrias culturales en el producto interno bruto de cinco países (Australia, Canadá, Estados Unidos, Francia y Reino Unido) se ha estimado en 3\%-6\% del PIB" (OCDE 2014 pág. 23).

\section{Ambientalización de la educación}

Ante las necesidades de formación, hoy se habla de una ambientalización de la educación que ayude a construir procesos pedagógicos y educativos, e inicien con la estimulación de una 
sensibilidad que conlleve a la comprensión del entorno cultural y del entorno ecosistémico (Noguera, 2004, p. 88, 89).

En tal sentido, para alcanzar la ambientalización de la educación es necesaria una estetización de la educación, la cual consiste en un amplio y significativo descubrimiento y comprensión del cuerpo como constructor de lenguajes (símbolos) y tejedor de contextos a favor de la relación de sentido con la naturaleza. Una estetización que tiene que ver con una redimensionalización de la sensibilidad, de la imaginación, de las dimensiones onírica, lúdica y de deseo, olvidadas durante el imperio de la razón científica moderna (Noguera, 2000, p. 95 53).

Como resultado de la aplicación de una ambientalización y estetización de la educación, el cuerpo alcanzaría su expresión y reconocimiento por ser "la gran metáfora del arte que se va vertiendo en diferentes materias desde la multiplicidad de los sentidos, pero también desde la unidad subjetiva como punto privilegiado donde el mundo se reduce a un órgano que parece dirigirnos no sólo toda la percepción sino la totalidad corporal; la percepción sensible del mundo, del cual depende el sentido de todas las cosas" (Fuenmayor 1999, p. 15).

Sin embargo, hoy se habla de una estetización del mundo de la vida la cual ha sido realizada a través de los medios de comunicación masivo y expresada por los "gustos individuales sobre toda otra forma de placer y felicidad" (Noguera, 2000, p. 66). Esta situación sucede porque la estética ha estado "omnipresente en todos los aspectos de la vida y pueden definirse como las emociones de vida, sentimientos, pasiones compartidas" (Maffesoli, 1992). Además porque "hay un placer estético en la vida cotidiana posmoderna, en el imaginario tribal, en todas las fusiones puntuales donde participan los objetos, lo que convierte la vida en una obra de arte" (Cova y Svanfeldt, 1992). La educación tiene la misión de traer el componente estético del mundo de la vida actual al aula, como una oportunidad para reflexionar en torno a las maneras como se está expresando creativamente el ser humano.

En tal sentido, el objeto de la educación y de la pedagogía, aún como supraobjeto, se rompe en mil pedazos, para dar paso a la concepción del mundo de la vida abierto, es decir, un mundo de la vida donde el abismo moderno entre el biologismo y el antropologismo desaparece, para dar paso a lo que llama Morin en 1972, la "soldadura epistemológica", donde ciencia y vida, técnica y vida, política y vida, ética y vida, arte y vida, entran en una relación inseparable y compleja, que abre la educación y la pedagogía a "una puerta que da a la noche" (Steiner, 1991), es decir a un lugar incierto, sin telos, sin 
destinos predeterminados, sin grandes utopías y sin predominio de grandes discursos o teóricas con pretensiones universalistas" (Noguera, 2000 p. 43).

Se necesita entonces, una pedagogía que vincule al pensamiento (ideas, reactualizaciones y recuerdos) con los sentimientos y las emociones, lo cual significa relacionar el pensamiento con el cuerpo; que tenga en cuenta otros aspectos que hacen parte del mundo de la vida cotidiano, como la intuición, las imágenes, las sensaciones, la poesía, el pensamiento mágico (Bohm, citado por Ballester y Colom, 2017 p. 61 ); que reconozca el lenguaje como componente vital del mundo de la vida en todas sus formas de ser -táctil, visual, auditivo, sonoro; que entienda que a través del arte podemos hacer una lectura de la cultura y de las formas estéticas en sus diversas manifestaciones simbólicas (Noguera, 2000, p. 89); que motive la conciencia de que el futuro saludable de la Tierra depende de la creación de una ciudadanía ambiental planetaria, la cual se basa en una ética integral de respeto a todos los seres con los cuales compartimos el planeta (Gadotti, 2003 p. 147). Una pedagogía con enfoque hermenéutico que haga consciente la finitud e historicidad como experiencia de auto-reflexión y hetero-reflexión para interpretar el mundo donde acontece lo humano (Noguera, 2000 p. 101). Una pedagogía asumida como conversación para el planteamiento y resolución de problemas que amplíe la visión del estudiante y docente sobre la realidad y la forma de percibir el mundo (Freire, 1985). En donde se practique una pedagogía crítica como una forma de pensar, negociar y transformar las relaciones entre la enseñanza en el aula, la producción de conocimiento, las estructuras institucionales de la escuela, y las relaciones sociales y materiales de la comunidad, la sociedad y la nación Estado (McLaren, 1998).

\section{La geopoética del habitar}

La propuesta pedagógica, retoma los aportes de Noguera (2014) respecto a la Geopoética del habitar. La cual hace alusión al estudio de la escritura que las culturas hacemos sobre la tierra. La idea consiste en valorar la relación espacio/tiempo, en la cual la cultura se ha manifestado a través de la idea de territorio/tiempo cronológico, mientras que la naturaleza se ha revelado en forma de ecosistemas/tiempo climático. En esta analogía, ha imperado la idea de dominio de lo interior sobre lo exterior, en donde la cultura se ha establecido en la naturaleza provocando unos cambios que han afectado la dinámica del ciclo vital.

La crítica al desarrollo, con todos sus adjetivos y prefijos que propone esta escritura, no es una crítica a un modelo de desarrollo, para proponer otro modelo, sino una crítica que permite proponer y acentuar la urgencia de una 
transformación de los símbolos de la cultura (Augusto Ángel-Maya, 1995), un cambio de rumbo de la cultura (Michel Serres, 1991), un habitar poéticamente esta tierra.

\section{La programación del curso historia del arte contemporáneo}

El curso propone el diseño de ambientes de aprendizaje que faciliten el análisis y la reflexión sobre el devenir histórico musical acaecido en la cultura occidental desde finales del siglo XIX hasta el momento actual (Ruiz, et al 2009). Desde esta perspectiva se tiene en cuenta que las distintas escuelas, movimientos y tendencias se generaron en contextos socioculturales concretos, que determinaron cambios en las mentalidades, las sensibilidades, las miradas $y$ las narrativas durante el siglo XX.

\section{Metodología}

La metodología implementada es de tipo cualitativo con enfoque descriptivo.

Se definieron 6 fases:

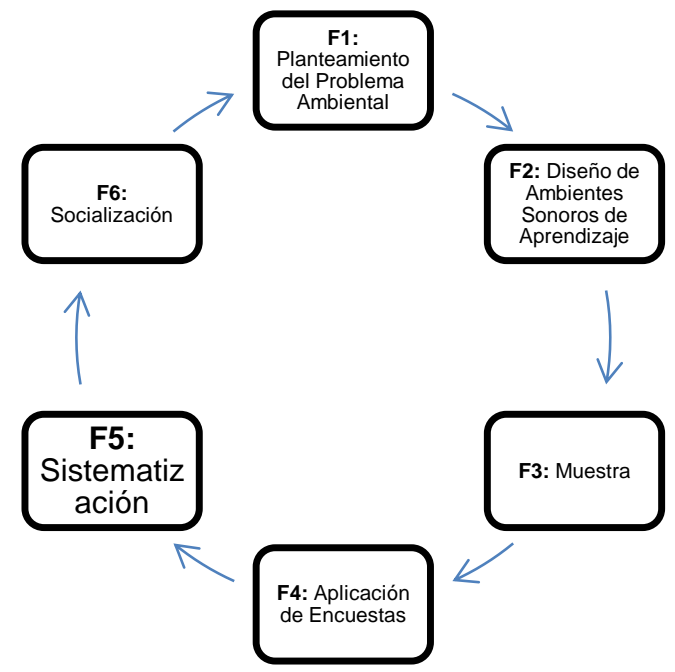

Fase 1: Planteamiento del problema ambiental: se llevó acabo en la primera parte del curso de Historia del Arte Contemporáneo, donde se contextualizó el devenir histórico europeo en relación a las composiciones musicales estudiadas.

Fase 2: Diseño de ambientes sonoros de aprendizaje: Se realizó en clase la audición de los temas musicales, así como el trabajo correspondiente al diseño de cada una de las estaciones de la Muestra.

Fase 3: Muestra de ambientes sonoros de aprendizaje: Se acondicionaron 6 espacios, aulas y auditorio, en el marco de la Muestra de Ambientes Sonoros de Aprendizaje realizada el 9 de mayo de 2018 (4:00 - 6:00 p.m.) en el Edificio de Artes.

Fase 4: Aplicación de encuestas: Se aplicó un cuestionario de seis (6) preguntas al grupo de estudiantes que diseñó las estaciones para la Muestra. Así mismo, un cuestionario de tres (3) preguntas para los grupos de estudiantes que visitaron la muestra.

Fase 5: Sistematización de respuestas: esta fase se llevó acabo por parte del docente investigador. El proceso de sistematización consistió en la organización de las respuestas dadas por parte de los estudiantes participantes, determinando en orden de importancia las palabras e ideas 
que más se repetían para marcar una tendencia colectiva.

Fase 6: Socialización de resultados y conclusiones: Se programó la conferencia titulada "Historia del Arte Contemporáneo, música y educación ambiental", la cual fue realizada el miércoles 9 de mayo de 2018 (10:00 -12:00 m. ) en el marco de la Agenda Cultural de la Facultad de Educación de la Universidad Surcolombiana.

Como parte del proceso, en la segunda fase, se escogieron seis obras del repertorio musical contemporáneo de finales del siglo XIX, así como del siglo XX, teniendo en cuenta la importancia que tuvieron en la línea del tiempo de la historia de la música. Dichas obras musicales fueron:

- "Cantos de creación de la tierra” (1972): música electroacústica de la compositora colombo-belga Jacqueline Nova Sondag. En esta obra convergen dos de los más grandes intereses de Nova: la voz humana y los medios electrónicos. La obra es una referencia obligada en la creación electroacústica latinoamericana de la década de los setenta, realizada con material vocal a partir de los cantos de la creación de la tierra de los indígenas U'wa (Romano, $\mathrm{s} / \mathrm{f}$ ).

- “El Danubio Azul” (1866): Vals del compositor austriaco Johann Strauss (hijo).
Comúnmente esta obra se asocia a la banda sonora de las fiestas de quince años que realizan las familias para presentar a sus hijas en sociedad. Sin embargo, muestra la sensibilidad del compositor hacia una maravilla de la naturaleza: el rio. Este afluente, recorre diez países europeos y cerca de 200 ríos le tributan sus aguas. La obra, es considerada el segundo himno nacional austriaco.

- “La Consagración de la primavera" (1913) Ballet del compositor ruso Igor Stravinsky. El titulo fue elegido debido a la antigüedad remotísima en que se sitúa la acción de sacrificar a una doncella a los dioses; la doncella debía bailar hasta morir con el fin de obtener la benevolencia de las deidades para con el pueblo ante la llegada de una nueva estación del año. La historia es protagonizada por una sociedad primitiva en una época de clanes y creencias mágicas en la religión. Esta obra es toda una evocación a la cópula, la contemplación de la naturaleza, la siembra, la evocación de los espíritus de las cosas y de los antepasados, hasta el hecho del crimen es organizado de manera festiva, en medio de los cantos y la música rítmica, en medio de una solemne celebración (Lasso, 2017).

- Música popular: En el contexto musical ha existido una división 
entre las músicas que constituían el estudio de la historia de la música, manifestado en la periodización europea, y las manifestaciones musicales que estaban por fuera de estas. Fue en los años ochenta, cuando los "popular music studies" "desvelaron la existencia de un campo de estudio muy productivo cuyas raíces provenían de los estudios de comunicación y cultura de masas de la Escuela de Fráncfort" (Spencer 2011, Pág. 38). Este paso dado en la musicología representó una polémica entre los investigadores pues hasta ese momento no se habían considerado para su reconocimiento, las dinámicas musicales en la modernidad. Sólo se habían aceptado como objeto de estudio la música clásica y la música folclórica. La música de masas, era considerada para los investigadores como “...popular, comercial, trivial, ligera, intrascendente o banal" (Sans, 2011 pág. 168). El interés por abordar el estudio de la música popular, y su relación con la cultura de masas, se convirtió en un campo fértil para los análisis musicológicos, pues acercó el oído a las nuevas concepciones de cultura constituidas desde las ciudades.

- "Pierrot Lunar" fragmento "La Noche" (1912): Esta obra corresponde al periodo de composición de obras atonales expresionistas del compositor austriaco Arnold Schoemberg. $\mathrm{Su}$ texto se basa en los poemas de A. Giraud. La importancia de Pierrot Lunaire radica, entre otros muchos motivos, en el hecho de servir de punto fronterizo, en marcar de forma clara una "fractura en la historia del arte musical" (LiscianiPetrini, 1999 citada por Fernández y Quintana, 2002 p. 215). "En Pierrot Lunaire advertimos en toda su profundidad la transformación que ha sufrido el lenguaje musical, con la aparición de figuraciones y materiales tímbricos inéditos, integrados en una totalidad que responde a una ley combinatoria interna a la misma. En ella el silencio se integra como un elemento estructural de primer orden. En todo caso, los recursos de los que se vale la nueva música tienen sin duda su origen en el movimiento inmanente a la música anterior, pero al mismo tiempo la nueva música se aleja de ésta a través de un evidente salto cualitativo. El octavo poema, comienza con notas graves de piano, se transmite una sensación de extrema gravedad, oscuridad y muerte, a ello se le añade la voz y los graves del cello. La noche se expande. La tensión crece en la segunda estrofa; el trémolo de la cuerda va caminando hacia un crescendo con el grave en fuerte del clarinete y cello" (Fernández y Quintana, 2002). 
- "El Manifiesto Futurista" (1913): Movimiento liderado por el compositor italiano Luigi Russolo el cual muestra la aparición del ruido en la vida cotidiana y el contraste del silencio que le antecedía. Russolo propone una música futurista la cual se basaba en el arte de los ruidos como consecuencia de la aparición de las máquinas. A partir de estas ideas, lanza el "Manifiesto Futurista" en el cual le sugiere al "músico futurista", ampliar y enriquecer cada vez más el campo de los sonidos, encontrar en los ruidos la manera de ampliarse y renovarse, construir una nueva orquesta de ruidos (Ivaldi, 2013).

\section{Universo}

La Facultad de Educación de la Universidad Surcolombiana para el periodo 2018-1, tuvo 429 estudiantes matriculados en los siguientes programas académicos:

\begin{tabular}{|c|c|c|c|}
\hline Programa & Mujeres & Hombres & Total \\
\hline $\begin{array}{c}\text { Licenciatura } \\
\text { en } \\
\text { educación } \\
\text { artística y } \\
\text { cultural }\end{array}$ & 91 & 96 & 187 \\
\hline $\begin{array}{c}\text { Licenciatura } \\
\text { en } \\
\text { educación } \\
\text { infantil }\end{array}$ & 150 & 92 & 242 \\
\hline Totales & $\mathbf{2 4 1}$ & $\mathbf{1 8 8}$ & $\mathbf{4 2 9}$ \\
\hline
\end{tabular}

Fuente: Sistema de Planeación y Programación académica (SIPPA) Universidad Surcolombiana. Año. 2017.

\section{Población}

La población de estudiantes participantes fue de 147, la cual corresponde a los siguientes grupos:

- Primer Grupo: 43 estudiantes matriculados en el curso de Historia del Arte Contemporáneo del Programa de Licenciatura en Educación Artística y Cultural, quienes participaron en las fases 1,2 , 3 , 4 y 5 (Planteamiento del Problema ambiental; diseño de Ambientes Sonoros de Aprendizaje; muestra de Ambientes Sonoros de Aprendizaje; aplicación de encuestas; sistematización de respuestas).

- Segundo Grupo: 56 estudiantes matriculados en el curso Historia del Arte Colombiano del programa de Licenciatura en Educación Artística y Cultural, quienes participaron en las fases $3 \mathrm{y}$ 4 (Muestra de Ambientes Sonoros de Aprendizaje y aplicación de encuestas).

- Tercer Grupo: 48 estudiantes matriculados en el curso Didáctica de la Música del Programa de Licenciatura en Educación Infantil, quienes participaron en las fases 3 y 4 (Muestra de Ambientes Sonoros de Aprendizaje y aplicación de encuestas). 


\section{Resultados}

A continuación se muestra la síntesis de las respuestas dadas por los grupos de estudiantes participantes:

\section{1. ¿Qué son los ambientes sonoros de aprendizaje?}

Los Ambientes Sonoros de Aprendizaje (ASA), son espacios académicos que promueven el aprendizaje vivencial a través de actividades que fomentan la imaginación y la creatividad. Toman como punto de partida la atención en lo sonoro desde donde se logra generar emociones que despiertan los sentidos y desarrolla una experiencia personal de relación con el entorno natural y cultural.

\section{2. ¿Qué aportan los ASA?:}

Contribuyen al desarrollo de procesos cognitivos a través de la vivencia de experiencias sensoriales.

- Promueven la sensibilización de problemáticas vigentes y la práctica del pensamiento crítico.

- Se vale de la música como canal de entrada para diseñar actividades que vivifican la relación no solo entre seres humanos, sino principalmente con todas las manifestaciones de vida.

- Favorecen el desarrollo de la confianza en sí mismo y en los demás.
- Promociona un aprendizaje vivencial que surge a partir de la interacción lúdica con los contenidos temáticos seleccionados.

- Resaltan el valor de la escucha y el silencio como componentes básicos del aprendizaje.

- Mejora la capacidad de atención y respuesta a las temáticas trabajadas.

- Estimula la creatividad en los diseñadores de los espacios así como en los participantes de los mismos.

- Promueve el trabajo en equipo, la asignación de funciones y el cumplimiento de compromisos definidos.

- Promueve estados de abstracción que favorecen el aprendizaje.

- Potencia el desarrollo de la imaginación y estimula la memoria sensitiva.

\section{3. ¿Qué materiales se usaron en la elaboración de los ambientes?}

A continuación se muestran los materiales usados en cada estación:

- "Cantos de creación de la tierra": Telones, arena, agua, hojas secas, piedras, pasto, ramas de palma, troncos de árbol, amplificador, ventilado, luces led, strover, vestidos indígenas, bastones, chicha, vino.

- "El Danubio Azul": video beam, computador, incienso, bombas, velos azules, luces, biombos, 
papel crepé, papel seda, cartón, botellas plásticas, vasos desechables, bolsas plásticas, trajes.

- "La Consagración de la primavera": plantas, pasto, tierra, piedras, arena, agua, bananos, limón, sal, incienso, piscina, caucho, bolsa plástica, sonajeros, parlantes.

- Música popular: papel craff, cinta, video beam, computador, luces, extensiones eléctricas, instrumentos musicales (bajo, guitarra eléctrica, batería) micrófonos, amplificadores.

- "Pierrot Lunar" fragmento "La Noche": discos compactos reutilizados, estrellas navideñas, mariposas, luces, cámara de humo, trajes de astronautas y de mariposas negras.

- "El Manifiesto Futurista": papel azúcar, máscaras, martillo, pulidora, taladro, luces, materiales de metal reciclados, herramientas (destornillador, llaves de expansión).

\section{4. ¿Qué actividades realizaron?}

\section{Cantos de creación de la tierra:}

- Información sobre la música indígena (U’wa) y la música electroacústica.

- Colocación de vendas en los ojos de los participantes.

- Recorrido guiado por el sendero construido para vivenciar los elementos aire, tierra, agua.

- Participación en el ritual de la creación.
- Conclusiones

\section{Danubio Azul:}

- Contextualización del siglo XIX.

- Explicación del nacionalismo musical del siglo XIX.

- Historia del rio Danubio.

- Problemáticas ambientales de los ríos.

Consagración de la primavera:

- Explicación del contexto histórico de la obra.

- Colocación de vendas en los ojos de los participantes.

- Recorrido por el circuito definido en forma circular.

- Vivencia de sabores, olores y texturas.

- Conclusiones.

\section{Música popular:}

- Explicación sobre el concepto de música popular.

- Análisis del TOP 20 de una emisora comercial.

- Exposición de nube de palabras a partir de las letras de las canciones del top 20 haciendo referencia de su relación con lo antropocéntrico y ambiental.

- Música popular en vivo.

Pierrot Lunar "La Noche":

- Ambientación sonora

- Dramatización del poema

- Reflexión

\section{Manifiesto Futurista:}

- Ingreso de participantes. 
- Escucha de un ambiente caótico industrial.

- Escucha de un ambiente natural con sonidos de aves.

- Reflexión

Al grupo de participantes se les formuló las siguientes preguntas:

\section{5. ¿Qué aprendió? Cantos de la tierra:}

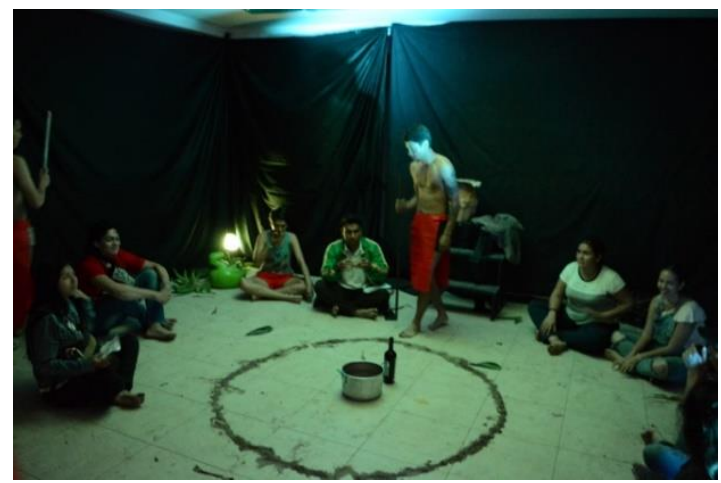

Fuente: Fotografía tomada por Jorge Bahamón. Universidad Surcolombiana. Edificio de artes. Año 2017.

Nos invitó a entrar en sintonía con la naturaleza y a relacionarnos con sus ritmos a través de los sentidos. Permitió el desarrollo de la imaginación a partir del uso de sentidos diferentes a la vista. La experimentación de sabores, texturas y sonidos nos despertó una sensación de asombro y la continua expectativa por lo que iba a suceder nos mantuvo en estado de atención. La actividad nos permitió transportarnos a otros lugares. Nos enseña que la tecnología ha absorbido la tradición. El tener los ojos vendados, me permitió aprender a confiar en otras personas y a que podemos ser más generosos con los demás. El desconocimiento del saber ancestral. La necesidad de apropiarnos de la cultura ancestral y dejar de lado el modelo de consumo que nos brinda la cultura occidental. La celebración del ritual sensibilizó mis sentidos. Me llevó a tocar la naturaleza. Aprendí a escuchar más y a valorar los sonidos de la naturaleza. También a tomar conciencia de la contaminación ambiental existente. Es importante el desarrollo de la imaginación en los procesos de activación del aprendizaje. Se evidenció la creatividad en el diseño de las actividades. Prescindir de la vista conllevó a experimentar otras sensaciones que permitieron conocer de otras maneras. A reflexionar sobre las consecuencias de la implementación de la tecnología y la industrialización sobre el sostenimiento de la tradición y las costumbres. A reflexionar sobre la relación entre música indígena y música electroacústica. Reflexionar sobre el impacto de las actividades humanas en la naturaleza. Pude percibir la música a través de mi oído y sentirla en todo mi cuerpo. Reflexionar sobre el cuidado de la naturaleza y sobre la necesidad de no depender tanto de los elementos tecnológicos. También sobre el olvido en que se encuentra la cultura ancestral. Acerca de la necesidad de cuidar los ecosistemas. La falta de conciencia hacia los problemas ambientales. La importancia de conocer la obra de la compositora Jacqueline Nova.

Manifiesto futurista: Aprendí a valorar los ruidos de la ciudad. A 
reconocer la contaminación sonora como un problema actual. Una vida llena de ruido es una vida llena de estrés. A más desarrollo más contaminación. El impacto de la contaminación sonora en la cotidianidad. Aprendí lo importante que es cuidar el ambiente sonoro. El impacto sonoro de las industrias en nuestra vida cotidiana. El ruido como opción de estudio. La forma como se crítica la influencia del capitalismo y la industria a partir del ruido. En la actualidad unas veces hacemos ruido por necesidad y otras por intensidad pero todo lleva a la contaminación. Encontrar la relación entre ruido, sonido, contaminación ambiental. El futuro de la relación entre clima y cultura. Es importante escuchar los mensajes de la naturaleza. El ruido y el caos también pueden aprovecharse para comunicar mensajes artísticos. La contaminación auditiva en que vivimos. Sentí añoranza de sonidos de la naturaleza libres de la contaminación sonora industrial. La necesidad de hacer un estudio de la relación entre ruido y capitalismo. La necesidad de desarrollar el pensamiento crítico. $\mathrm{Al}$ comienzo el ruido molestó un poco, pero después se halló el sentido de todo. La incomodidad del ruido industrial urbano y el contrate con las zonas rurales. Los constantes ruidos a los que estamos expuestos a diario en la ciudad que afecta el contacto con los sonidos de la naturaleza. Acerca de la necesidad de reflexionar sobre la contaminación sonora que sufrimos a diario.
Como se ha subestimado la influencia del arte en la sociedad. La cotidianidad del ruido y la aceptación que ha alcanzado. Como a través del ruido se puede infundir miedo y como a través de éste nos pueden dominar. La creatividad que se puede alcanzar a través de la exploración de los ruidos. Acerca de los ruidos que generan las industrias y todos los motores que mueven el desarrollo moderno y la manera como afectan nuestro entorno y nuestro diario vivir. La manera como nos hicieron entrar en razón sobre la forma en que vivimos. Aprendí a disfrutar los momentos de silencio. Como el ruido puede ser aprovechado como materia sonora para convertirla en música. Se logró plasmar la monotonía o rutina en la que vivimos, a pesar de tanto ruido expresaron la realidad. Nunca creí que de esa manera se pudiera expresar la realidad. No debemos cambiar los sonidos de la naturaleza por ruidos contaminantes. Acerca del significado que porta cada sonido/ruido. Se vio reflejado el fastidio que le provocamos a los demás a través del ruido. La forma de mostrarnos sin censura, como vivimos ahora en el caos del ruido. El caos de la ciudad se ve reflejado en el acelere de las personas y en el ruido que provocan. Al comienzo no me sentí cómoda en ese lugar. Luego comprendí que se necesitaba simplemente ordenar los ruidos o sonidos para crear música y generar tranquilidad. Realcé mi conocimiento sobre la contaminación sonora industrial y la modernización. 


\section{Danubio azul:}

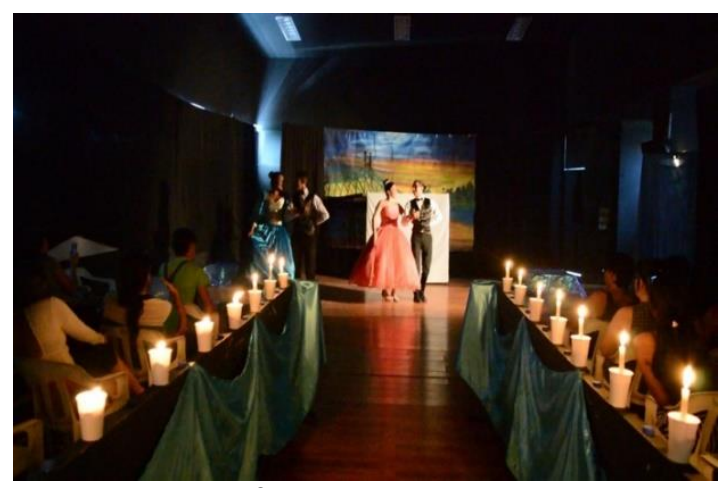

Fuente: Fotografía tomada por Jorge Bahamón. Universidad Surcolombiana. Edificio de artes. Año 2017.

Aprendí sobre la contaminación de los ríos y sobre la necesidad actual de encontrar soluciones para no contaminarlos más y cuidarlos porque son fuente de vida. A reconocer que el río hace parte de nuestra existencia. A reflexionar sobre el ocaso de los ríos y el ocaso de la especie humana. Crítica a la sociedad europea por la contaminación del rio Danubio. La invasión de basuras en los ríos. La posibilidad de describir el rio a través de la expresión corporal. La dependencia hacia los ríos que tiene el ser humano. La manera como se pierde naturaleza a cambio de cosas que no son tan importantes. Aprendí sobre geografía y su relación con la contaminación. Acerca de la necesidad de reflexionar sobre nuestro habitar y el de los demás seres vivos.

\section{Consagración de la Primavera:}

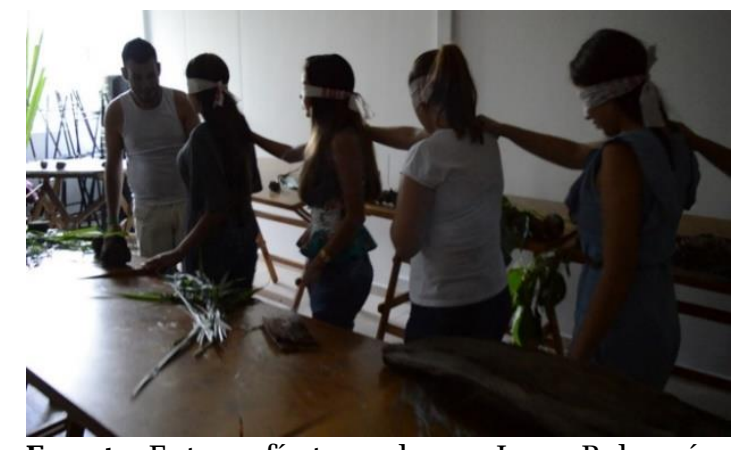

Fuente: Fotografía tomada por Jorge Bahamón. Universidad Surcolombiana. Edificio de artes. Año 2017

Sobre la conservación de la cultura ancestral. A potenciar los sentidos. Aprendí a valorar más lo que nos rodea. A explorar el mundo a través de los olores y a tener contacto continuo con la naturaleza. La exploración de los sentidos y como vemos más cosas sin el sentido de la vista. La necesidad de buscar tranquilidad para encontrarnos con la naturaleza. Toda una fiesta de sensaciones. Expresividad de la primavera. El misterio de la naturaleza. Me llamó la atención como el hombre está perdiendo las verdaderas riquezas. El juego de lo sonoro y del gusto da dinamicidad para interactuar con el tema ambiental. El juego de los sentidos. El ejercicio desarrolló en mí la confianza en otra persona. También la experimentación de sensaciones diferentes y el encuentro con lo desconocido. La ambientación logró transportarme a la selva. Se pudo admirar lo hermoso que es la primavera ya que nos dejamos llevar de nuestros sentidos para aprender a admirar lo gratificante que es interactuar con la naturaleza. Valorar el gusto como canal de entrada para el desarrollo de aprendizajes. 
Aprendí a contextualizar los sonidos a través de las texturas y los sabores. La bendición que trae la naturaleza. El necesario contacto con la naturaleza. La interacción con sabores, texturas y sonidos permitió la comprensión total del mensaje: la necesidad de asombrarnos con la naturaleza. El desarrollo de la creatividad para transportarnos a otros lugares con la imaginación. Generó expectativa por lo nuevo que iba a pasar. La dependencia que tenemos hacia el sentido de la vista. La posibilidad de limitar el sentido de la vista permitió sentir las cosas de manera diferente. Fue una oportunidad para tener la naturaleza a flor de piel. Debemos amar la naturaleza. Podemos aprender sobre la naturaleza disfrutándola. La utilización del tacto para reconocer las cosas. La fusión de sentidos para experimentar. Me sentí empoderada de nuestra madre tierra, con las cosas que nos brinda y que nos falta conocer. De una manera tan sencilla, la exploración de los sentidos permitió aumentar la capacidad de percibir. Nos contribuye a comprender lo importante que son nuestros sentidos para explorar el mundo y comunicarnos entre nosotros. La transportación que se alcanzó hacia el bosque. La necesidad de guardar silencio para escuchar.

Pierrot Lunar:

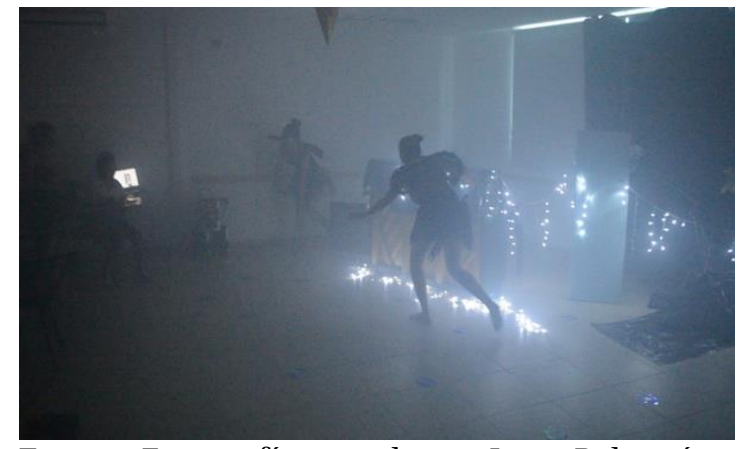

Fuente: Fotografía tomada por Jorge Bahamón. Universidad Surcolombiana. Edificio de artes. Año 2017

Se logró percibir un ambiente tenso. Que el ser humano con su accionar provoca la muerte de especies animales. Me gustó la puesta en escena. Me gustó el ambiente y la actuación. La combinación de música, ambiente y baile. La luz y la interpretación del poema. La relación entre la luz y la sombra. Como el ser humano destruye y se apropia de los otros seres de este mundo. La utilización del humo y de la dramatización. La creación de nuevos sistemas musicales. Aprendí que el ser humo en su afán por descubrir nuevas cosas puede afectar ecosistemas y provocar daños irreparables.

\section{Música Popular:}

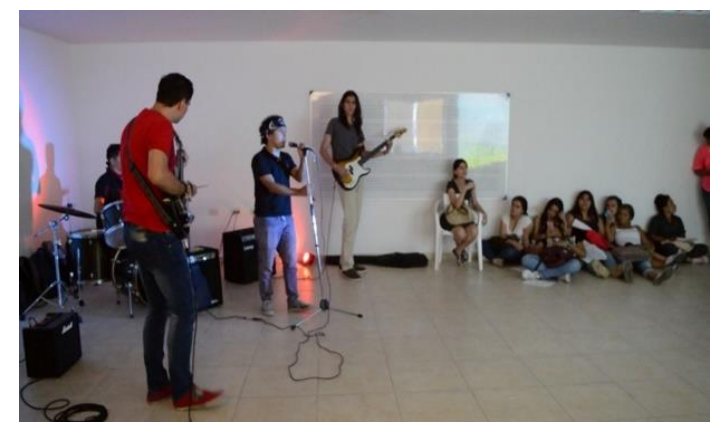

Fuente: Fotografía tomada por Jorge Bahamón. Universidad Surcolombiana. Edificio de artes. Año 2018. 
Sobre la discriminación que se hace a través de las letras de las canciones. El impacto de la música popular en las tradiciones. La música popular es la más reconocida en este tiempo. Que la música popular va más allá de la que se escucha en las cantinas. El reconocimiento de la música popular como tema de trabajo. Acerca del concepto de música popular. La necesidad de reflexionar sobre el vocabulario de algunas canciones de música popular. Sobre el uso que se le da a la música popular en esta época. La influencia de los medios de comunicación en la conformación de los gustos musicales. El significado social de la música popular. Como el capitalismo está ligado con la producción de la música popular. Me gustó la música en vivo. La necesidad de reflexionar sobre el consumo musical. La creación de estereotipo a través de la música. La influencia de la música popular en la sociedad moderna. La influencia del consumo en la vida cotidiana. La música popular utiliza las palabras mujer y amor para cautivar pero en últimas la música no habla de eso.

\section{Conclusiones}

La situación actual de crisis ambiental preocupa a los jóvenes universitarios, lo que se ve reflejado en la puesta en escena de temas como la contaminación de los ríos y la contaminación sonora. Así mismo, en la sensibilidad expresada hacia las consecuencias de la forma como estamos habitando el planeta.

La vivencia de una pedagogía que articule el pensamiento con los sentimientos y las emociones, es una oportunidad para estetizar el mundo de la vida cotidiana con lo cual se pueden encontrar respuestas a las problemáticas ambientales existentes.

Una educación ambiental pertinente debe promover el dialogo entre la naturaleza y la cultura reconociendo las expresiones de lo biótico y lo simbólico; a la vez, debe propender por la reeducación del sentido del habitar incorporando el estudio de los ciclos de la naturaleza, buscando alternativas de cambio a las consecuencias generadas por el metabolismo socioeconómico y reconociendo un sentido de alteridad amplio que incluya todas las manifestaciones de vida existentes. Una educación ambiental coherente con la situación actual, debe reconocer que la especie humana no es protagonista única, estamos para acompañar toda la escena ambiental que nos alimenta.

La propuesta de diseñar Ambientes Sonoros de Aprendizaje, se une a la idea de ambientalizar la educación, por cuanto reconoce el proceso de estetización activado mediante el descubrimiento y comprensión del cuerpo como constructor de lenguajes y tejedor de contextos a favor de la relación de sentido con la naturaleza (Noguera, 2000). Por 
lo cual, se activa una redimensionalización de la sensibilidad, la imaginación, la creatividad y la lúdica, fundamentos esenciales para la comprensión del entorno ecosistémico y su relación con el entorno cultural. Una manera particular de sentir y escribir en el mundo.

\section{Referencias}

Angel-maya, A (1995) La fragilidad ambiental de la cultura. Bogotá: IDEA - UN.

Ángel-Maya, A. (2013) El Reto de la Vida. Publicación en línea https://webcache.googleuserc ontent.com/search?q=cache:df dWblWIasUJ:https://rds.org.co /apc-aa-

files/ba03645a7c069b5ed406f 13122a61c07/el_reto_de_la_vi da.pdf $+\& c d=1 \& h l=e s \& c t=c l n k \&$ $\mathrm{gl}=\mathrm{CO}$

Bauman y Mazzeo (2013). Sobre la Educación en un mundo líquido. Barcelona, España: Paidós.

Ballester y Colom (2017). Epistemologías de la complejidad y educación. Barcelona, España: Editorial Octaedro.

Cova y Svanfeldt (1992) Societal innovations and the postmodern aestheticization of everyday life. Recuperado de https://www.researchgate.net/ publication/256431763_Societ al_innovations_and_the_postm odern_aestheticization_of_ever yday_life

Delgado et al. (2013). Crisis Socioambiental y Cambio Climático. Buenos Aires, Argentina: CLACSO.

Fernández D. y Quintana H. (2002). Anotaciones Filosóficomusicales a propósito de Pierrot Lunaire de Arnold Schonberg. Boletín Millares Carlo. Recuperado de http://mdc.ulpgc.es/cdm/ref/ collection/bolmc/id/320

Fischer-Kowalski y Haberl (2000). El Metabolismo Socioeconómico.Departamento de Ecología Social del Interdisciplinary Institute of Research and Continuing Education (IFF) recuperado de https://es.scribd.com/docume nt/281530189/El-

Metabolismo-SocioeconomicoFischer-y-Kowalski

Freire, P. (1985). Pedagogía del Oprimido. Montevideo, Tierra Nueva: Siglo XXI Editores.

Fuenmayor, V. (1999). El Cuerpo de la Obra. Universidad del Zulia. Maracaibo, Venezuela. Recuperado de https://es.scribd.com/docume nt/247508812/Cuerpo-de-LaObra-1-de-Victor-Fuenmayor

Gadotti, M (2003) Perspectivas actuales de la educación. Buenos Aires, Argentina: Siglo XXI Editores. Recuperado de https://issuu.com/mazzymaz 
zy/docs/perspectivas_actuales _de_la_educaci

Guerrero, P. (2002). La Cultura, Estrategias conceptuales para entender la identidad, la diversidad, la alteridad y la diferencia. Escuela de Antropología Aplicada. Quito, Ecuador; Ediciones Abya-Yala.

Heidegger, M. (1994). Conferencias y Artículos. Eustaquio Barjau (traducción). Madrid, España: Ediciones del Serba.

Hinkelammert, F. (2006). Prometeo, el discernimiento de los dioses y la ética del sujeto. Recuperado de https://journals.openedition.o $\mathrm{rg} /$ polis/5527

Ivaldi, E. (2013). El Arte de los ruidos. Revista Que hacer Educativo. Recuperado de http://webcache.googleuserco ntent.com/search?q=cache: 249 qQgaRZAgJ:www.fumtep.edu.u y/index.php/component/k2/it em/download/904_ed4ea3479 dbf64e3c08cbb1aa76a2e 4e+\&c $\mathrm{d}=10 \& \mathrm{hl}=\mathrm{es} \& \mathrm{ct}=\mathrm{clnk} \& \mathrm{gl}=\mathrm{cO}$

Lasso, A. (2017). Análisis hacia la interpretación de la Danza del Sacrificio en La Consagración de la Primavera de Igor Stravinsky. Recuperado de http://bdigital.unal.edu.co/57 359/7/AlexanderLassoRubio.2 017.pdf

Maffesoli, M. (1992). La transfiguración de lo político: la trivialización del mundo postmoderno. Editorial Herder.

McLaren, $\quad P$.

Multiculturalismo

Revolucionario. Siglo XXI Editores.

http://funama.org/data/PEDA

GOGIA\%20CRITICA/mclaren/M

ulticulturalismo\%20Revolucion ario.pdf

Noguera, A.P. (2000) Educación Estética y Complejidad Ambiental. Universidad Nacional de Colombia. Sede Manizales. Recuperado el 6 de octubre de 2016 http://www.bdigital.unal.edu.c o/7076/1/anapatricianoguera deecheverri.2000.pdf

Noguera, A. P. (2004). El Reencantamiento del Mundo. Universidad Nacional de Colombia. Sede Manizales. Recuperado el 6 de octubre de 2016

http://www.bdigital.unal.edu.c o/5963/2/9687913312.pdf

Noguera, A.P. (2012). Crisis Ambiental: Pérdida del Cuerpo y de la Tierra. Recuperado el 8 de septiembre de 2017 http://vip.ucaldas.edu.co/cult uraydroga/downloads/Cultura ydroga17(19)_12.pdf

Noguera, A. (2014). Geopoética del habitar sur. Recuperado de http://www.sustentabilidades. usach.cl/sites/sustentable/file s/paginas/05_0.pdf 
OCDE (2014). ¿El arte por el arte? Centro para la Investigación e Innovación Educativas. Recuperado de https://www.oecd.org/edu/cer i/ES_ARTS_overview_V5_print. pdf

Pineda, J. (2014). Geopoética de la guerra: he oído música en el estruendo del combate $y$ he hallado paz donde las bombas escupían fuego. Recuperado de http://studylib.es/doc/786780 0/geopo\%C3\%A9tica-de-laguerra---he-o\%C3\%ADdom\%C3\%BAsica-en-el

Romano, A. (s/f). Homenaje a la precursora de la música electroacústica en Colombia: Jacqueline Nova Sondag. Recuperado de http://www.mincultura.gov.co /prensa/noticias/Paginas/Hom enaje-a-la-precursora-de-lamusica-electroacustica-enColombia-Jacqueline-NovaSondag.aspx

Ruiz, J. et al (2009). Microdiseño del curso Historia del Arte Contemporáneo. Licenciatura en Educación Artística y Cultural. Universidad Surcolombiana.

Serres, M. (1991) El Contrato Natural. Paris: Pre-Textos.

Steiner, G.(1991) En el Castillo de Barba Azul. Aproximaciones a un nuevo concepto de Cultura. Barcelona: Gedisa. 